\title{
VENDER TABACO À ESCALA DO REINO: A DISTRIBUIÇÃO NO MONOPÓLIO PORTUGUÊS (1721-1722)
}

\author{
SELLING TOBACCO ACROSS THE KINGDOM: \\ DISTRIBUTION UNDER THE PORTUGUESE \\ MONOPOLY (1721-1722)
}

\author{
Susana Münch Miranda \\ GHES/CSG - ISEG \\ Universidade de Lisboa
}

\section{RESUMO}

Este artigo examina as estratégias organizacionais que os contratadores-gerais, Willem de Bruijn e Paulo Cloots, implementaram para operacionalizar a distribuição de tabaco no mercado doméstico português. A análise dessas estratégias permite concluir que o consórcio holandês pôs em prática soluções inovadoras na comercialização do tabaco que tiveram um impacte positivo nas provedorias do Sul do país. A comparação com as provedorias do Centro e Norte de Portugal mostra também que foi no Sul que o consórcio holandês conseguiu mitigar conflitos de agência.

Palavras-chave: arrendamento fiscal, negociantes, consumo, inovação organizacional, conflitos de agência, tabaco.

\section{ABSTRACT}

This article examines the organizational strategies put in place by Willem de Bruijn and Paulo Cloots, as general farmers of the Portuguese tobacco monopoly, to distribute tobacco in the metropolitan market. It concludes that the Dutch consortium innovated through organizational changes that positively impacted sales in the southern districts of Portugal. The comparison with the central and northern districts also shows that the Dutch tax farmers were able to mitigate agency problems in the South.

Keywords: tax-farming, businessmen, innovation, organizational changes, consumption, principal-agent problem, tobacco. 


\section{RESUM \\ VENDRE TABAC A ESCALA DEL REGNE: LA DISTRUBUCIÓ AL MONOPOLI PORTUGUÉS (1721-1722)}

A aquest article ens centrem en les estratègies organitzatives que els comptadors generals, Willem de Bruijn i Paulo Cloots, implementaren per gestionar a la distribució de tabac al mercat portuguès. L'anàlisi de les seves estratègies permet concloure que el consorci holandès va ficar en pràctica solucions innovadores a la comercialització de tabac que van tenir un impacte positiu a les vendes a les províncies del sud del país. La comparació amb les vendes de les zones del centre y del nord de Portugal mostren també que fou al sud on el consorci holandès va aconseguir mitigar els problemes d'agència.

Paraules clau: homes de negoci, innovació, canvis organitzatius, consum, problemes d'agència.

\section{RESUMEN}

\section{VENDER TABACO A ESCALA DEL REINO: LA DISTRIBUCIÓN EN EL MONOPOLIO PORTUGUÉS (1721-1722)}

En este artículo examinamos las estrategias organizativas que los contadores generales, Willem de Bruijn y Paulo Cloots, implementaron para operar en la distribución de tabaco en el mercado portugués. El análisis de tales estrategias permite concluir que el consorcio holandés puso en práctica soluciones innovadoras en la comercialización de tabaco que tuvieron un impacto positivo en las ventas en las provincias del sur del país. La comparación con las ventas en las zonas centro y norte de Portugal muestran también que fue en el sur donde el consorcio holandés consiguió mitigar los problemas de agencia.

Palabras clave: hombres de negocios, innovación, cambios organizativos, consumo, problemas de agencia. 


\section{INTRODUÇãO}

As fontes que permitem examinar as estruturas organizacionais e as orientações estratégicas de empreendimentos mercantis ou financeiros no período pré-industrial são escassas, como é bem conhecido. Um número relativamente reduzido de livros de razão e de correspondência mercantil sobreviveu até aos nossos dias, realidade que, aliás, tem obstado ao rápido desenvolvimento de uma história empresarial comparada no espaço e no tempo para a Idade Moderna. ${ }^{1} O$ conhecimento disponível sobre a principal forma de organização empresarial nesta cronologia - a empresa familiar - permanece, pois, limitado em virtude desta insuficiência documental. ${ }^{2}$ Pese embora esta limitação, estudos recentes em história empresarial têm insistido na forte influência do contexto institucional e económico na evolução dinâmica das organizações empresariais, na esteira dos es-

1 GelDERBLOM, Oscar e TRIVELLATO, Francesca (2018), "The Business History of the Preindustrial World: Towards a Comparative Historical Analysis", Business History, vol. 60/5, pp. $1-35$.

2 Não existe uma definição única de empresa familiar que possa ser utilizada transversalmente no espaço e no tempo. Todavia, tem-se aceite uma definição genérica, segundo a qual podemos dizer que estamos perante uma empresa familiar quando a família possui um capital próprio suficiente para poder exercer o controlo sobre a estratégia empresarial. Sobre este assunto, vejam-se COLLI, Andrea e FERNÁNDEZ, Paloma (2013), "Business History and Family Firms", in MELIN, Leif, NORDQVIST, Mattias e SHARMA, Pramodita (eds.), Sage Handbook of Family Business, Sage, Londres, pp. 269-292; e COLLI, Andrea e ROSE, Mary (2007), "Family Business", in JONES, Geoffrey G. e ZEITLIN, Jonathan (eds.), The Oxford Handbook of Business History, Oxford University Press, Oxford, pp. 194-217. 
tudos seminais de Ronald Coase, Oliver Williamson e Douglass North. ${ }^{3}$ À luz deste modelo teórico, tem-se vindo a reconhecer a importância que as "regras formais do jogo" determinadas pela moldura legal e institucional vigente, como direitos de propriedade, o sistema de taxação vigente, o direito sucessório e o direito das falências, tinham nas opções estratégicas das empresas familiares. ${ }^{4}$

No caso de estudo que aqui se apresenta, o contexto institucional do monopólio português do tabaco fornece o grande pano de fundo em que se inscrevem as opções organizacionais e estratégicas de uma firma holandesa, a casa de Willem de Bruijn e Paulo Cloots, que explorou este negócio na década de 1720. Reconhece-se que as regras concebidas pela monarquia para a extração de uma renda fiscal sobre a venda de tabaco no mercado doméstico impuseram constrangimentos, as 'regras formais do jogo', aos privados que contrataram a exploração do negócio desde 1702, quando esta prática se tornou corrente. Esta circunstância já foi, aliás, reconhecida pela literatura. ${ }^{5} \mathrm{Um}$ estudo prévio dedicado a esta firma, em particular à gestão dos dois contratos que detiveram entre 1722 e 1727 e que teve como desfecho uma situação de incumprimento, chamou também a atenção para esses constrangimentos, bem como para fatores conjunturais e contingentes. ${ }^{6}$ Neste artigo, o enfoque desloca-se das causas do insucesso para a observação detalhada das estratégias de operacionalização de

3 NORTH, Douglass C. (1981), Structure and Change in Economic History, W.W. Norton \& Co., New York, pp. 37 e 45-58. Para uma visão geral sobre os contributos de Ronald Coase e Oliver Williamson, veja-se JONES, Stephen (1997), "Transaction Costs and the Theory of the Firm: The Scope and Limitations of the Institutional Approach", Business History, vol. 39/4, pp. 9-25. Para um exemplo da aplicação da teoria da firma a um estudo de caso, veja-se GELDERBLOM, Oscar (2003), "The Governance of Early Modern Trade: The Case of Hans Thijs, 1556-1611", Enterprise and Society, vol. 4/4, pp. 606-639.

4 MATHIAS, Peter (2000), "Risk, Credit and Kinship in Early Modern Enterprise", in McCUSKER, John e MORGAN, Kenneth (eds.), The Early Modern Atlantic Economy, Cambridge University Press, Cambridge, pp. 15-35; COLLI e ROSE, "Family Business"; e SAFLEY, Thomas Max (2009), "Business Failure and Civil Scandal in Early Modern Europe", Business History Review, vol. 83/1, pp. 35-60.

5 SALVADO, João Paulo (2014), "O estanco do tabaco em Portugal: contrato-geral e consórcios mercantis, 1720-1755", in LUXÁN, Santiago de (ed.), Política y Hacienda del tabaco en los imperios ibéricos (siglos XVII-XIX), Centro de Estudios Políticos e Constitucionales, Madrid.

6 MIRANDA, Susana Münch (2018), "Risco e expectativas no monopólio português do tabaco, 1722-1727", in LUXÁN, Santiago de e FIGUEIROA-REGO, João (eds.), El tabaco y la esclavitud en la rearticulación imperial ibérica (ss. XVII-XX), CIDEHUS / Universidade de Évora, Évora. 
um dos três segmentos em que se desdobrava a execução do contrato: a distribuição no mercado doméstico.?

Olhar para o segmento da distribuição, pressupõe reconhecer que o quadro normativo de um monopólio com preços administrados era, ainda assim, suficientemente flexível para permitir que os consórcios privados organizassem livremente partes do negócio. Esta constatação foi feita recentemente, quando se chamou a atenção para o potencial explicativo de inovações organizacionais no sucesso dos contratos do estanco português depois da década de $1760 .{ }^{8}$ Algumas destas inovações tocaram a aquisição da matéria-prima, mas também a distribuição sofreu dinâmicas ainda na primeira metade do século XVIII que, provavelmente, concorreram para uma mais eficaz gestão dos contratos. ${ }^{9}$ Este artigo dialoga com os resultados destas investigações recentes e o seu contributo reside numa análise dos desafios e problemas da venda de tabaco à escala nacional, bem como das opções organizativas tomadas pelos contratadores. Tem como base empírica dois códices de correspondência que Willem de Bruijn e Paulo Cloots mantiveram com os comarqueiros e administradores das comarcas no início do primeiro triénio, mais concretamente entre Novembro de 1721 e Novembro de $1722 .{ }^{10}$ Pouco frequente, esta tipologia documental permite descortinar aspetos porventura menos conhecidos da gestão quotidiana da distribuição do tabaco na primeira metade do século XVIII, que complementam o retrato já traçado por Margarida Machado para os Açores do início do século XIX. ${ }^{11}$

A secção seguinte começa por recordar o modelo organizacional do estanco português do tabaco e as modalidades em que se realizou a sua exploração entre 1674 e 1752, prosseguindo depois com uma breve incursão pelas principais características do segmento da distribuição. É neste pano

7 Sobre estes três segmentos - aquisição, transformação e distribuição -, veja-se COSTA, Leonor Freire e SALVADO, João Paulo (2018), "Consumo, inovação organizacional e fiscalidade do tabaco em Portugal, 1701-1803", in LUXÁN e FIGUEIROA-REGO (eds.), El tabaco y la esclavitud.

8 COSTA e SALVADO, "Consumo, inovação organizacional e fiscalidade".

9 SALVADO, João Paulo, (2018), "Uma revolução de escala? O impacte do estanco no comércio de tabaco brasileiro (Lisboa, primeira metade do século XVIII)", in LUXÁN e FIGUEIROA-REGO (eds.), El tabaco y la esclavitud.

10 Arquivo Nacional da Torre do Tombo (ANTT), Junta da Administração do Tabaco (JAT), livros 206 e 209.

11 MACHADO, Margarida (2018), "Os contratadores do tabaco nos arquipélagos atlânticos dos Açores e da Madeira", in LUXÁN e FIGUEIROA-REGO (eds.), El tabaco y la esclavitud. 
de fundo que se insere o caso de estudo de De Bruijn e Cloots observado detalhadamente o que vamos a observar.

\section{O modelo organizacional do estanco português do tabaco e O Segmento DA DISTRIBUIC̣Ão}

Falar da organização do estanco português do tabaco implica recordar que nele se reflete a política imperial da monarquia, moldada pela vontade de conciliar os interesses fiscais metropolitanos com os interesses coloniais. Desde logo, este objetivo evidenciou-se na forma como os princípios gerais do estanco se foram definindo ainda na década de 1640. Por um lado, os interesses de plantadores e de negociantes do reino alinharam-se em 1649 com os da fiscalidade régia, quando, numa tentativa de reforçar a integração económica entre a colónia e a metrópole, o tabaco brasileiro se tornou fonte exclusiva de abastecimento ao estanco. Proibiu-se o cultivo de tabaco em contexto doméstico, estimulando-se a produção colonial também por meio de legislação que vedava a importação de tabaco da América espanhola e da Virgínia. Consequentemente, os contratadores dependiam em exclusivo da matéria-prima produzida na capitania da Bahia e adquirida em Lisboa junto das casas mercantis que se dedicavam à importação. ${ }^{12}$ Por outro lado, se a coroa autorizou a exportação direta de tabaco para a costa ocidental africana para sustentar o comércio de escravos, protegeu também o mercado metropolitano reservando-lhe o tabaco de superior qualidade. ${ }^{13}$ Acresce ainda que, para conciliar os interesses nem sempre convergentes de plantadores, importadores e contratadores do estanco doméstico, se impôs aos plantadores um preço máximo de venda, muito embora esta medida tivesse tido um sucesso limitado. ${ }^{14}$ Não obstante, a política imperial portuguesa conseguiu um melhor equilíbrio dos interesses metropolitanos e coloniais do que a Espanha ou a França, garantindo não só o abastecimento de tabaco brasileiro ao mercado doméstico e para alguns mercados europeus de reexportação, como proporcionando também

12 NARDI, Jean-Baptiste (1996), O fumo brasileiro no período colonial: lavoura, comércio e administração, Editora Brasiliense, São Paulo, pp. $112-113$.

13 NARDI, Jean-Baptiste (1990), "Retrato de uma indústria no Antigo Regime: o estanco real do tabaco em Portugal, 1675-1830", Arquivos do Centro Cultural Português, vol. 28, pp. 895897.

14 SCHWARTZ, Stuart B. (1984), "Colonial Brazil, Plantations and Peripheries, c. 1580-c. 1750", in BETHELL, Leslie (ed.), The Cambridge History of Latin America. Colonial Latin America, vol. 2, Cambridge University Press, Cambridge, pp. 423-499; e NARDI, O fumo brasileiro, pp. 106-107. 
ao Estado uma significativa fonte de receita fiscal por via do exclusivo de venda no mercado doméstico. ${ }^{15}$

Para esse efeito, há que recordar que, além da obrigatoriedade do abastecimento de tabaco brasileiro, este monopólio se caracterizava também pela existência de preços administrados, isto é, por preços diretamente tabelados pela coroa para a venda por grosso e a retalho. ${ }^{16}$ Para os contratadores-gerais, esta norma significava, na prática, que uma exploração bem sucedida do monopólio dependia da quantidade de consumo de tabaco. Qualquer variação negativa das vendas podia pôr em risco o cumprimento das condições contratualizadas com a monarquia, mormente as mensalidades entregues à Junta da Administração do Tabaco. Dependendo da tipologia do tabaco em oferta no mercado, os preços por grosso e miúdo apresentavam escalas variáveis, tendo subido em duas ocasiões no século XVIII. Depois do primeiro aumento em 1702, o segundo, que entrou em vigor em Janeiro de 1722, implicou um agravamento do preço para o consumidor em $20 \%$ nas qualidades de maior procura, e uma redução das margens brutas na distribuição por grosso, na ordem dos $140 \% .{ }^{17}$ Nestas circunstâncias, a distribuição a retalho adquiriu uma importância reforçada para a casa holandesa De Bruijn e Cloots que assumiu a exploração do monopólio precisamente em Janeiro de 1722. A forma como organizaram este segmento inscreveu-se, todavia, nos parâmetros que as reformas institucionais de 1674 tinham estabelecido para o monopólio, a começar pela quadrícula territorial que utilizaram para organizar a venda à escala regional.

Na verdade, desde que a Junta da Administração do Tabaco fora encarregue de gerir o monopólio em 1674, utilizavam-se as circunscrições em que se subdividia territorialmente a administração da fazenda, mais concretamente as provedorias, para estruturar a distribuição regional. $O$ espaço metropolitano subdividia-se em vinte e uma comarcas de provedoria, se tomarmos como ponto de referência a viragem para o século XVIII. Um provedor encabeçava cada uma dessas comarcas, cabendo-lhe supervisionar a cobrança fiscal regional executada pelos almoxarifes. Articulando diretamente com as instituições centrais sediadas em Lisboa, os provedores

15 Sobre esta comparação, veja-se, PRICE, Jacob (1995), "Tobacco Use and Tobacco Taxation: A Battle of Interests in Early Modern Europe", in GOODMAN, Jordan, LOVEJOY, Paul E. e SHERRATT, Andrew (eds.), Consuming Habits: Drugs in History and Anthropology, Routledge, Londres, pp. 165-185.

16 SALVADO, "O estanco do tabaco em Portugal".

17 MIRANDA, "Risco e expectativas". 
asseguravam, pois, a comunicação e intermediação com os almoxarifados e seus oficiais. Note-se que, nalguns casos, a malha da administração da fazenda se sobrepunha à quadrícula judicial, pelo que certas provedorias podiam coincidir territorialmente com os limites das comarcas. Ourique, Beja, Portalegre, Setúbal, Santarém, Castelo Branco e Guarda constituem exemplos desta coincidência, que também se verificava nas ilhas dos Açores e Madeira. Na ótica da monarquia, a opção pela quadrícula preexistente visava mobilizar os oficiais superiores da administração periférica, provedores e corregedores, no combate à fraude e ao contrabando e no cumprimento das normas definidas para a distribuição. Vale a pena notar que esta quadrícula de base se manteve, mesmo depois de 1702, quando se transitou para a exploração do monopólio por privados. ${ }^{18}$

Para o segmento da distribuição, as reformas de 1674 tiveram ainda uma segunda implicação relevante com a criação da fábrica de Lisboa. Sendo o monopólio português assente no consumo de tabaco em pó, com esta medida procurou-se centralizar a transformação da matéria-prima e controlar as quantidades de tabaco remetidas para a distribuição. A contratualização com privados depois de 1702 veio reformular o papel da fábrica de Lisboa no contexto do estanco. Nos anos subsequentes, criaram-se quatro novas manufaturas - Porto, Madeira, Terceira e S. Miguel - para melhor aproximar os centros de produção de tabaco transformado aos mercados regionais e assim reduzir custos de operacionalização. Se, com esta inovação, a fábrica de Lisboa perdeu o exclusivo da transformação, ganhou o exclusivo da compra de tabaco em bruto e a responsabilidade de proceder à sua redistribuição pelas demais. De qualquer modo, Lisboa continuou a ser a fábrica mais relevante do estanco, assegurando a produção e o abastecimento de tabaco em pó e em folha das provedorias do Centro e Sul do país a que correspondia mais de metade do consumo total. A do Porto, por seu turno, assegurava a transformação e a distribuição de tabaco pelas provedorias do Norte do país (Minho, Trás-os-Montes e parte da Beira). A uma escala apenas regional, as fábricas da Madeira, São Miguel e Terceira, criadas por volta de 1713, respondiam à procura dos principais centros urbanos insulares. ${ }^{19}$ Mais do que meras unidades transformadoras, as fábricas concentravam informação atualizada sobre o tabaco distribuído, e logo sobre as tendências do consumo, o que fazia delas peças axiais de controlo sobre o estanco. ${ }^{20}$

18 SALVADO, "O estanco do tabaco em Portugal".

19 NARDI, "Retrato de uma indústria no Antigo Regime", pp. 895-897.

20 SALVADO, "O estanco do tabaco em Portugal". 
Esta moldura institucional comportou decorrências relevantes para os contratadores-gerais. Desde logo, porque a divisão implícita do espaço continental em duas grandes áreas - Sul/Centro e Norte, abastecidas respetivamente por Lisboa e pelo Porto - teve tradução na forma como se organizavam internamente para repartir responsabilidades na supervisão da produção e distribuição do tabaco. Assim, não surpreende a opção por uma estrutura bipartida, coincidindo com os dois grandes centros de redistribuição, Lisboa e Porto. Como já se constatou, aliás, os consórcios incluíam frequentemente influentes negociantes do Porto, capazes de mobilizar as redes de negócio locais, a quem caberia a operacionalização do estanco nas provedorias do Norte. Em Lisboa, por seu turno, ficava sediada a supervisão, não só da distribuição regional e suprarregional, como também a monitorização superior do estanco, encabeçada pelo líder do consórcio, a quem competia igualmente assegurar toda a comunicação financeira e administrativa com a Junta da Administração do Tabaco.

A quadrícula territorial definida em 1674, por seu turno, não impôs constrangimentos aos contratadores. Por um lado, as condições contratuais davam-lhes liberdade para organizar territorialmente o negócio como bem entendessem, muito embora se optasse, na prática, por utilizar também as provedorias como unidade administrativa de base para a distribuição. No replicar desta solução estaria também da parte dos privados o reconhecimento de que haveria vantagens em concitar a administração periférica da monarquia em matéria de justiça e fazenda para a execução do contrato. Por outro lado, os contratadores-gerais tinham inteira liberdade para escoIher o regime de gestão que melhor assegurasse a distribuição regional de tabaco. A escolha fazia-se entre o subarrendamento ou a administração direta das unidades territoriais. $O$ subarrendamento implicava o trespasse dos direitos de exploração, por meio de uma escritura pública, a um rendeiro, tendo como contrapartida o pagamento de um preço anual previamente acordado entre as partes. Nesta modalidade, cabia ao rendeiro organizar a venda a retalho, conduzida nos chamados estancos, equivalentes aos estanquillos da Renta del Tabaco. ${ }^{21}$ Optando pela administração

21 RODRÍGUEZ GORDILLO, José Manuel (2000), "El abastecimiento de tabacos del Brasil a las Reales Fábricas de Sevilla en el primer tercio del siglo XVIII", in Actas del Coloquio de Historia Canario-Americana, Cabildo Insular de Gran Canaria, Las Palmas de Gran Canaria, pp. 1879-1881; e ESCOBEDO, Rafael, "La desprivatización de la hacienda española durante el siglo XVIII: el ejemplo del monopolio de tabacos", Empresa y Humanismo, vol. 8/2, 2006, p. 58. 
direta da provedoria, os contratadores-gerais nomeavam um administrador que, em seu nome organizaria a venda a retalho no interior da sua circunscrição. Nesta modalidade, o contratador-geral eliminava o rendeiro, chamando a si o resultado líquido das vendas a retalho, depois de deduzidos os custos da distribuição. Note-se que, em provedorias com elevado volume de negócio, era comum a existência de sub-administrações, que enquadravam os estancos e os seus estanqueiros e que respondiam perante 0 administrador principal. ${ }^{22}$

Sendo estas as opções disponíveis, a literatura já demonstrou que nas primeiras décadas do século XVIII os consórcios optaram por um modelo misto, que combinava arrendamento e administração direta das circunscrições territoriais em graus diversos, dependendo dos interesses próprios de cada um dos consórcios. Em regra, todavia, as sociedades tendiam a manter a venda a retalho em Lisboa e no Porto sob administração direta, por motivos relacionados com a dimensão destes mercados urbanos e o seu peso relativo no consumo total do estanco metropolitano. Ainda nesta cronologia, fortes indícios apontam para que a administração direta se tenha paulatinamente tornado a opção preferida pelos contratadores-gerais, muito embora esta tendência ainda necessite de investigação mais aprofundada. Certo é que Feliciano Velho Oldenberg, que liderou a exploração do monopólio entre 1741 e 1752, pôs pela primeira vez em prática a administração direta da totalidade do estanco, incluindo as ilhas atlânticas. Se nos anos subsequentes se voltou ainda ao modelo misto, no último quartel do século XVIII a administração direta da venda a retalho tornar-se-ia a modalidade de exploração sistematicamente adotada pelos contratadores-gerais. ${ }^{23}$

\section{A GESTÃo DE DE BRUIJN \& CLOOTS}

Estabelecidos em Lisboa desde 1713, os negociantes holandeses de Amsterdão Willem de Bruijn e Paulo Cloots, em sociedade com Arnaldo van Zeller, um holandês de segunda geração, arremataram o contrato do tabaco para o triénio de 1722 a $1724 .{ }^{24}$ Pelo exclusivo de transformação e venda de tabaco brasileiro no mercado doméstico comprometeram-se a pagar 720.000 .000 réis por ano à fazenda real. Este preço seria satisfeito por meio de mensalidades no valor de 46.000 .000 réis, acrescidas de pagamentos suplementares trimestrais de 42.000 .000 réis. Além do preço, o consórcio assumiu todos os custos de operacionalização do es-

22 Refira-se, como exemplo, os sub-administradores de Tavira e Silves na provedoria do Algarve.

23 COSTA e SALVADO, "Consumo, inovação organizacional e fiscalidade". 
tanco, que compreendiam a aquisição da matéria-prima, o funcionamento das fábricas, os custos de transporte do tabaco entre fábricas e para as circunscrições regionais, bem como os salários da Junta da Administração do Tabaco.

Tal como sucedia com os contratadores-gerais que os precederam, De Bruiin e Cloots tiveram um prazo muito curto para organizar a gestão do monopólio. Entre a adjudicação do estanco, no dia 16 de novembro de 1721, e o início do contrato a 1 de janeiro de 1722, tomaram várias decisões relativas à estrutura de supervisão e às modalidades de exploração das unidades territoriais para a distribuição. Arnaldo van Zeller foi enviado para o Porto onde passaria a residir, com a incumbência de coordenar as atividades que tivessem a ver com a futura execução do contrato na zona norte do país. A partir de janeiro de 1721, esperava-se que supervisionasse a laboração da fábrica e o abastecimento de tabaco às provedorias do Minho, Trás-os-Montes e Beira. Por seu turno, De Bruijn e Cloots mantiveram o seu assento em Lisboa e, enquanto sócios maioritários, iniciaram de imediato a seleção das propostas de arrendamento que lhes foram apresentadas por consórcios mercantis regionais. Em final de novembro, arrendaram as províncias do Minho, Trás-os-Montes e quatro das sete provedorias da Beira. Duas semanas volvidas, adjudicaram as restantes circunscrições territoriais que planeavam concessionar. No mesmo espaço de tempo, procederam à escolha dos administradores que, em seu nome, se encarregariam de distribuir tabaco no Alentejo, província que, desde o início, planearam manter em exploração direta. ${ }^{25}$

Destas diligências, conclui-se que a estratégia de gestão deste consórcio holandês para o segmento da distribuição estava em linha de continuidade com o que tinha sido prática corrente entre os seus predecessores, na medida em que optaram pelo modelo misto. Inovaram, todavia, na proporção de circunscrições territoriais que mantiveram em administração directa. ${ }^{26}$ Para efeitos da exploração, De Bruijn e Cloots dividiram o territó-

24 Sobre a casa de Willem de Bruijn e Paulo Cloots e as suas actividades mercantis e financeiras, veja-se ANTUNES, Cátia, MIRANDA, Susana Münch e SALVADO, João Paulo (2018), "The Resources of Others: Dutch Exploitation of European Expansion and Empires, 1570-1800", Tijdschrift voor Geschiedenis, vol. 131/3, pp. 501-521. Veja-se também uma síntese em MlRANDA, "Risco e expectativas".

25 ANTT, JAT, liv. 206, fls. 1v-2, carta a Arnaldo van Zeller, Porto, 1721-11-29; idem, liv. 209, fls. 1v-2, carta a Arnaldo van Zeller, Porto, 172 1-12-13.

26 ANTT, JAT, liv. 209, fls. 1v-2, carta a Arnaldo van Zeller, Porto, 1721-12-13. 
rio metropolitano e os arquipélagos atlânticos em dezanove unidades, de dimensão variável e congregando circunscrições administrativas diversas (províncias, provedorias e comarcas). Destas arrendaram doze: Açores, Castelo Branco e Pinhel, Coimbra e Esgueira, Guarda, Leiria, Madeira, Minho, Santarém, Tomar, Torres Vedras, Trás-os-Montes e Lamego, e Viseu. Chamaram a si a exploração direta das duas principais cidades - Lisboa e Porto - bem como de mais sete unidades, todas elas a sul do Tejo: Algarve, Beja e Campo de Ourique, Elvas, Estremoz, Évora, Portalegre e Setúbal (Quadro n. ${ }^{\circ} 1$ ). A sua inserção prévia em redes mercantis no sul do país, em particular no Alentejo, para aquisição de lã em bruto e azeite, e a informação que dispunham do mercado e dos agentes económicos regionais certamente favoreceram esta opção. ${ }^{27}$ Também a natureza do povoamento concentrado típico do Sul oferecia melhores condições para o controlo territorial da venda a retalho.

Diferentemente, a Beira e a região norte do país, mais povoadas e com redes mercantis mais dinâmicas e logo menos disponíveis para aceitar o papel subalterno das administrações, condicionaram as opções dos contratadores-gerais e impuseram o arrendamento. Nesta modalidade, o concessionário recebia o exclusivo da distribuição de tabaco por um preço acordado, chamando a si os custos da operacionalização e o resultado líquido das vendas na unidade territorial contratada. Como era prática corrente, a cedência fazia-se por escritura pública de arrendamento, onde se consagravam as condições gerais ajustadas entre as partes. Uma delas dizia respeito ao pagamento do preço da concessão, que replicava a frequência das entregas feitas pelos contratadores-gerais à fazenda real, com a repartição em mensalidades e quartéis, pagos antecipadamente. Por fim, também estes contratos exigiam fianças, para garantia do que, afinal de contas, era o subarrendamento de uma renda pública. ${ }^{28}$ As administrações ajustavam-se igualmente por escritura notarial, mas pouco se sabe de concreto quanto ao tipo de vínculo e às contrapartidas negociadas. Em qualquer caso, o contrato visava formalizar a relação entre o administrador e

\section{ANTUNES, MIRANDA e SALVADO, "The Resources of Others".}

28 Os contratos de arrendamento não são conhecidos porque os cartórios notariais onde estes contratos se registaram foram destruídos pelo terramoto de 1755. Sabemos, todavia, que os contratos de cedência e trespasse das provedorias se realizaram em Lisboa, entre finais de novembro e no decurso de dezembro de 1721 (Arquivo Distrital de Lisboa, Cartórios Notariais de Lisboa, Distribuidor, liv. 85, fls. 40v-41). A correspondência com os arrendatários das provedorias permite conhecer indiretamente as condições contratuais (ANTT, JAT, liv. 206, fls. $1-5)$. 
Quadro 1

Unidades territoriais e modalidade de exploração (1722-1724)

\begin{tabular}{|c|c|c|c|}
\hline $\begin{array}{l}\text { Unidade } \\
\text { territorial }\end{array}$ & $\begin{array}{l}\text { Divisão } \\
\text { geográfica ou } \\
\text { administrativa }\end{array}$ & $\begin{array}{l}\text { Rendeiro ou } \\
\text { administrador }\end{array}$ & $\begin{array}{l}\text { Modalidade } \\
\text { de administração }\end{array}$ \\
\hline Açores & Provedoria & Vasco Lourenço Veloso & Arrendamento \\
\hline Algarve & Provedoria & Bento de Araújo & Administração direta \\
\hline $\begin{array}{l}\text { Beja e Campo de } \\
\text { Ourique }\end{array}$ & Provedorias & $\begin{array}{l}\text { Pedro Fermín } \\
\text { de Sobia } \\
\text { (depois } \\
\text { José Francisco Gomes) }\end{array}$ & Administração direta \\
\hline $\begin{array}{l}\text { Castelo Branco } \\
\text { e Pinhel }\end{array}$ & Provedorias & Diogo Soares Franco & Arrendamento \\
\hline Coimbra e Esgueira & Provedorias & $\begin{array}{l}\text { Manuel da Cruz } \\
\text { Mascarenhas }\end{array}$ & Arrendamento \\
\hline Elvas & Provedoria & João Rodrigues Bagulho & Administração direta \\
\hline Estremoz & Comarca & José Rebelo Pereira & Administração direta \\
\hline Évora & Provedoria & Bento Vieira da Cunha & Administração direta \\
\hline Guarda & Provedoria & Pedro Vaz da Silva & Arrendamento \\
\hline Leiria & Provedoria & Carlos Ferreira da Costa & Arrendamento \\
\hline Madeira & Provedoria & Manuel Martins Rocha & Arrendamento \\
\hline Minho & Província & António Mendes Álvares & Arrendamento \\
\hline Portalegre & Provedoria & António Rodrigues da Santa & Administração direta \\
\hline Santarém & Provedoria & José Cristóvão da Costa & Arrendamento \\
\hline Setúbal & Provedoria & Gabriel Ferreira & Administração direta \\
\hline Tomar & Provedoria & Domingos Pereira Guimarães & Arrendamento \\
\hline Torres Vedras & Provedoria & José Pessoa de Leão & Arrendamento \\
\hline $\begin{array}{l}\text { Trás-os-Montes e } \\
\text { Lamego }\end{array}$ & $\begin{array}{l}\text { Província e } \\
\text { Provedoria }\end{array}$ & Baltazar Lopes Franco & Arrendamento \\
\hline Viseu & Provedoria & $\begin{array}{l}\text { Manuel de Loureiro (depois } \\
\text { Manuel Furtado de Mendonça) }\end{array}$ & Arrendamento \\
\hline
\end{tabular}

Fonte: ANTT, JAT, livros 206 e 250. 
o contratador-geral, consagrando os termos da prestação de serviços a realizar pelo primeiro. Por seu intermédio, o administrador comprometia-se a gerir a exploração de uma determinada unidade em nome do contratador-geral, o que implicava a supervisão das vendas a retalho a cargo dos estanqueiros. Como contrapartida, e não havendo cedência de direitos sobre o monopólio, tudo indica que receberia uma comissão sobre as vendas, à semelhança do que estava em vigor para a administração dos Açores nos finais do Antigo Regime. ${ }^{29}$ Estes contratos podiam ser rescindidos a qualquer momento, o que flexibilizava a eventual substituição de agentes que não cumprissem as cláusulas contratuais, em contraste com a rigidez dos contratos de arrendamento.

A correspondência trocada entre De Bruijn e Cloots, por um lado, com os rendeiros e administradores das provedorias, e por outro, com Arnaldo van Zeller, permite surpreender o funcionamento quotidiano desta complexa máquina destinada a assegurar a distribuição de tabaco à escala nacional. Os parágrafos seguintes exploram três dimensões essenciais da gestão do negócio: a logística, o controlo do consumo e a monitorização dos agentes. A análise destes vetores permite melhor avaliar os desafios relacionados, quer com as exigências de explorar um monopólio baseado no consumo, cujo sucesso dependia das quantidades vendidas, quer com os entraves colocados à circulação de bens e mercadorias em contexto português.

O transporte de tabaco de Lisboa para a fábrica do Porto e para as provedorias ocupou um espaço central na gestão quotidiana do estanco. No triénio de 1722-1724, este consórcio colocou 1.214 toneladas de tabaco, em rolo e em pó, no mercado doméstico, das quais perto de 614 toneladas foram expedidas para a fábrica do Porto. ${ }^{30}$ Para De Bruijn e Cloots, tal como para os seus antecessores e sucessores, a movimentação de semelhantes volumes de mercadoria levantou desafios, agravados pela fraca rede de transportes que caracterizava o Portugal metropolitano. Se o extenso litoral facilitava a comunicação marítima entre Lisboa e o Porto, uma rede hidrográfica pouco densa e de fraco caudal dificultava a navegação para o interior, limitada apenas a dois rios, o Tejo e o Douro. Nestas circunstâncias, o acesso a grande parte do interior fazia-se com recurso à rede viária, que seguia ainda a matriz definida pelas estradas romanas. Desenvolvia-se numa linha paralela à costa atlântica, cujo eixo principal ligava a foz do rio Guadiana até Lisboa, seguindo depois de Lisboa até ao

29 MACHADO, "Os contratadores do tabaco nos arquipélagos atlânticos".

30 MIRANDA, "Risco e expectativas". 
rio Minho. Em torno desse eixo, outras vias de comunicação articulavam com o interior, muito embora a sua densidade dependesse das variações do relevo terrestre. ${ }^{31}$ Sendo estas as condicionantes, e seguindo critérios ditados pela oportunidade, pelas condições climáticas e pelos custos, De Bruijn e Cloots combinaram o recurso a transportes marítimos, fluviais e terrestres para operar a distribuição. As expedições para o Porto evidenciam bem esta realidade.

Como seria expectável, o consórcio demonstrou preferência pelo transporte marítimo para assegurar o abastecimento da fábrica do Porto, menos oneroso do que o transporte terrestre. $O$ tabaco embarcava-se em navios portugueses ou estrangeiros a troco do pagamento de fretes. Foi esta a modalidade de transporte utilizada para expedir, no dia 24 de novembro de 1721 , os primeiros 150 rolos de tabaco destinados ao abastecimento das provedorias do Norte após transformação. ${ }^{32}$ Entre esta data e o dia 4 de fevereiro de 1722, o consórcio enviou por via marítima 67.566 libras de tabaco em rolo e 10.989 libras de pó, nas variedades de simonte e cidade, distribuídas por sete remessas. ${ }^{33}$ Concomitantemente, também nas semanas que antecederam o início do contrato, os holandeses recorreram ao envio de tabaco para o Porto, fazendo uso da rede fluvial e da rede viária. Fizeram-no atendendo às circunstâncias excecionais que rodeavam o início de cada triénio. Não só porque o arranque da execução coincidia com os meses de Inverno, altura em que a oferta de transporte marítimo era mais reduzida, como também porque se tratava de colocar largas quantidades de tabaco em bruto para garantir o início da laboração da manufatura do Porto, sendo ainda necessário garantir que houvesse tabaco já transformado que pudesse ser lançado nos circuitos de distribuição regional do Norte nas primeiras semanas de 1722. Neste caso, o tabaco expedia-se por via fluvial até ao porto de Tancos, a partir do qual se carregava em bestas muares, conduzidas por almocreves. Entre 26 de Novembro e 27 de Janeiro de 1722, De Bruijn e Cloots fizeram sete remessas por esta via, totalizando 49.600 libras de rolo e 13.855 libras de pó. ${ }^{34}$ Queixaram-se,

31 MATOS, Artur Teodoro de (1980), Transportes e comunicações em Portugal, Açores e Madeira, 1750-1850, Universidade dos Açores, Ponta Delgada, pp. 15-16.

32 ANTT, JAT, liv. 206, fl. 1v-2, carta a Arnaldo van Zeller, Porto, 1721-12-06; idem, fl. 44, carta a António Mendes Álvares, Porto, 1722-02-14; idem, liv. 85, fl. 5.

33 ANTT, JAT, liv. 85, fls. 3-4v. Medida antiga de peso, o arrátel ou libra portuguesa, correspondia a 458,96 gramas.

34 ANTT, JAT, liv. 85, fl. 13 e ss.; idem, liv. 206, fl. 1, carta a Manuel Martins da Costa, Tancos, 1721-11-26. 
todavia, dos custos exorbitantes com a expedição terrestre para a fábrica do Porto e da reduzida oferta de animais para realizar o transporte desta mercadoria pesada e volumosa. ${ }^{35}$

Além de abastecer o Porto com tabaco em bruto, à fábrica de Lisboa competia fornecer as províncias da Estremadura, uma parte da Beira (Guarda e Castelo Branco), o Alentejo e o Algarve e de tabaco transformado. ${ }^{36}$ Para a Estremadura e para a Beira, combinava-se novamente a rede fluvial com a rede viária, usando como nódulo de articulação o porto de Tancos. Pela sua importância como placa giratória na expedição de tabacos para aquelas regiões, o consórcio dispunha de um comissário em Tancos, de nome Manuel Martins da Costa, incumbido de coordenar as cargas com a rede de almocreves. ${ }^{37}$ Nenhum eixo articulador semelhante se encontra replicado para o transporte de tabacos a sul do Tejo, onde a prevalência de um relevo plano favorecia as comunicações terrestres e a penetração para o interior. As remessas de tabaco para o Alentejo e Algarve faziam-se, pois, por meio de almocreves. ${ }^{38}$ As expedições faziam-se a um ritmo variável, na proporção da capacidade de consumo regional, pelo que os dados seguintes servem apenas como indicação. No ano de 1722, as remessas tiveram uma cadência quinzenal para Santarém, Beja e Campo de Ourique, mensal para a Guarda, Castelo Branco e Estremoz. ${ }^{39}$ Sobre o transporte de tabaco para as provedorias do Norte pouco se sabe. A sua responsabilidade cabia à fábrica do Porto, para a qual não existe documentação, pública ou privada, que tenha sobrevivido até aos nossos dias.

Tão importantes quanto as expedições regionais de tabaco eram as transferências mensais para Lisboa, cruciais para o cumprimento atempado da entrega das mensalidades e dos quartéis junto da fazenda real. De uma forma geral, as remessas do valor mensal dos arrendamentos e do procedido líquido das vendas nas administrações faziam-se em moeda. Só pontualmente se transferiam receitas da fábrica do Porto por letras da terra, intermediadas por casas mercantis inglesas. ${ }^{40} \mathrm{~A}$ circulação das remessas à escala nacional decalcava, no essencial, o circuito das expedições do

35 ANTT, JAT, liv. 209, fls. 1 e 2, cartas a Arnaldo van Zeller, Porto, 1721-12-06 e 1721-12-13.

36 ANTT, JAT, liv. 85.

37 Manuel Martins da Costa era o comissário do consórcio que estava em Tancos (ANTT, JAT, liv. 206, fl. 1, 1721-11-26).

38 ANTT, JAT, liv. 206, fl. 5, carta a Bento Vieira da Cunha, Évora, 1721-12-16; idem, liv. 206, fl. 64, carta a Bento de Araújo Barbosa, Faro, 1722-03-17.

39 ANTT, JAT, liv. 85, fls. 70-73, 180-183, 130-134 e 240-243v. 
tabaco. Assim, os créditos das provedorias sob a alçada de Van Zeller Minho, Trás-os-Montes e parte da Beira - encaminhavam-se para o Porto. A única exceção eram as provedorias de Coimbra e Esgueira que, embora abastecidas pela fábrica do Norte, remetiam o valor do arrendamento para Lisboa. A partir do Porto, Arnaldo van Zeller tinha a incumbência de remeter as mensalidades para os seus sócios. Garantir que estas remessas chegassem a Lisboa nos primeiros dias de cada mês, antes do prazo limite que a fazenda real impunha aos contratadores-gerais (10 de cada mês) foi uma preocupação constante para De Bruijn e Cloots. Montaram um circuito mensal que, articulando o Porto, Coimbra e Lisboa, exigia uma boa coordenação entre as partes, por envolver a transferência das receitas da fábrica do Porto, das mensalidades das provedorias do Norte e das de Coimbra e Esgueira. Este circuito era operado por oficiais escolhidos por si, que, partindo do Porto, passavam por Coimbra no dia 28 de cada mês, tendo chegada prevista a Lisboa no primeiro ou segundo dias do mês seguinte. ${ }^{41}$ Para que este calendário fosse cumprido, impunha-se aos estanqueiros da cidade do Porto e aos rendeiros que fizessem as entregas de numerário a Arnaldo van Zeller até ao dia 25 de cada mês. ${ }^{42}$ Por seu turno, as remessas dos créditos da fábrica do Porto, em moeda ou em letras, tinham uma cadência superior - quinzenal ou mesmo semanal -, fazendo-se o seu envio pelo correio ordinário, operado por estafetas que ligavam Lisboa ao Porto. ${ }^{43}$

Das provedorias a sul do Tejo, os fluxos monetários para Lisboa circulavam pela rede de almocreves, não se divisando nenhum circuito articulador. A

40 ANTT, JAT, liv. 206, fl. 94 e 103, cartas a Arnaldo van Zeller, Porto, 1722-05-09 e 1722-0523. As letras da terra funcionavam de forma similar às letras de câmbio, diferindo apenas no facto de se utilizarem em contexto nacional. Sobre a sua utilização em Portugal no século XVIII, veja-se ROCHA, Manuela e SOUSA, Rita Martins de (2005), "Moeda e crédito", in LAINS, Pedro e SILVA, Álvaro Ferreira da (eds.), História Económica de Portugal (1700-2000), Imprensa de Ciências Sociais, Lisboa, pp. 227-229.

41 ANTT, JAT, liv. 206, fls. 42 e 43v, cartas a Arnaldo van Zeller e André Carneiro de Sousa, Porto, 1722-02-10 e 1722-02-13; idem, fl. 57, carta a Manuel da Cruz Mascarenhas, Coimbra, 1722-03-07.

42 ANTT, JAT, liv. 206, fl. 42, carta a Arnaldo van Zeller e André Carneiro, Porto, 1722-02-10.

43 ANTT, JAT, liv. 206, fls. 119 e 125, cartas a Arnaldo van Zeller, Porto, 1722-06-13 e 172206-20. Sobre o correio ordinário deste período, que garantia uma ligação semanal entre Lisboa e Braga, tocando Coimbra, Aveiro e o Porto, veja-se NETO, Margarida Sobral (2005), "Os correios na Idade Moderna", in NETO, Margarida Sobral (ed.), As Comunicações na Idade Moderna, Fundação Portuguesa das Comunicações, Lisboa, pp. 19 e ss. 
todos os seus administradores, De Bruijn e Cloots impunham igualmente a cobrança da receita das vendas aos estanqueiros até ao dia 25 de cada mês, para não comprometer a sua chegada atempada a Lisboa. ${ }^{44}$ Pontualmente, receitas regionais do tabaco transferiam-se para a capital por meio de serviços financeiros prestados pelo consórcio holandês a outros negociantes e a instituições da coroa que quisessem transferir créditos para outros pontos do país. Nessas ocasiões, o consórcio holandês operava como uma instituição para-bancária, emitindo letras a pagar pela sua rede de comarqueiros e administradores, por conta das receitas regionais do tabaco. ${ }^{45}$

No caso das ilhas atlânticas, cedidas por contrato de arrendamento, os fluxos financeiros seguiam um padrão diverso. A exploração dos Açores estava entregue a Vasco Lourenço Veloso, um dos maiores negociantes da praça de Lisboa, com quem a casa holandesa mantinha boas relações. ${ }^{46}$ Estabelecido na capital, Vasco Lourenço geria a distribuição de tabaco nas ilhas por intermédio de agentes, pelo que as mensalidades seriam entregues em mão a De Bruijn e Cloots. No que respeita à provedoria da Madeira, os holandeses viram nas transferências a crédito uma oportunidade de negócio internacional, devidamente explorada com recurso à sua extensa rede de parceiros. O rendeiro, Manuel Martins da Rocha, tinha ordem para entregar todos os meses o valor dos arrendamentos à firma Hayward \& Rider, casa mercantil inglesa, especializada no comércio de vinho da Madeira. ${ }^{47}$ Esta casa, por seu turno, tinha instruções para adquirir vinhos e aguardentes e de os remeter para Amsterdão, a Daniel de Bruijn, irmão de Willem de Bruijn. ${ }^{48} \mathrm{Na}$ falta de bons vinho, Hayward \& Rider tinham

44 ANTT, JAT, liv. 206, fls. 40v-4 1v, cartas a João Rodrigues Bagulho, Portalegre, Bento Vieira da Cunha, Évora, e António Rodrigues da Santa, Portalegre, 1722-02-10.

45 ANTT, JAT, liv. 206, fl. 104, carta a António Mendes Álvares, 1722-05-23; idem, fl. 120, carta a Bento de Araújo Barbosa, Faro, 1722-06-16. Uma destas operações envolveu a Junta dos Três Estados que transferiu um pagamento ao vedor-geral do exército do Alentejo, por meio de uma letra emitida pelo consórcio holandês e paga pelo administrador em Portalegre (ANTT, JAT, liv. 206, fl. 100, carta a João Rodrigues Bagulho, Portalegre, 1722-05-19).

46 Além da "boa amizade" que os unia a Vasco Lourenço Veloso, De Bruijn e Cloots recorreram diversas vezes ao irmão, João Lourenço Veloso, para agenciar negócios na Bahia, onde este último estava sediado. ANTT, JAT, liv. 208, fl. 235, carta a João Lourenço Veloso, 18-04-1727.

47 Sobre a casa de Joseph Hayward e William Rider, veja-se HANCOCK, David (2002), "'An Undiscovered Ocean of Commerce Laid Open': India, Wine and the Emerging Atlantic Economy, 1703-1813", in BOWEN, Huw V., LINCOLN, Margarette e RIGBY, Nigel (eds.), The Worlds of the East India Company, Boydell Press, Woodbridge, pp. 155-156.

48 ANTT, JAT, liv. 209, fl. 80, carta a Hayward \& Rider, ilha da Madeira, 1722-05-08. 
instruções para adquirir casquinha, uma conserva de fruta geralmente de casca de citrinos, a enviar para Lisboa. ${ }^{49}$ Nestas operações, De Bruijn e Cloots souberam aproveitar a crescente procura de vinho da Madeira nos mercados do Norte da Europa, usando o contrato-geral do tabaco para financiar outros negócios onde podiam fazer mais-valias acrescidas. As ligações marítimas livres entre as ilhas atlânticas e as principais escápulas europeias facilitaram indubitavelmente estas operações.

Num monopólio de venda com preços administrados, o controlo do mercado e das quantidades vendidas era fundamental para o sucesso do contrato-geral. Se esta era uma preocupação comum aos contratadores, no caso vertente assumia ainda maior importância, atendendo à entrada em vigor do novo tabelamento de preços em janeiro de 1722 e à incógnita que seria o comportamento dos consumidores. Acresce ainda que, em Dezembro de 1721, já havia indícios suficientes que o contratador-geral cessante estava a vender ilegalmente grandes quantidades de tabaco no Porto e nas provedorias do Norte, a preço abaixo do tabelado, pondo em risco a execução do contrato seguinte. ${ }^{50}$ Neste contexto, não é, pois, surpreendente que na correspondência trocada com rendeiros e administradores circule um elevado número de informações sobre as dinâmicas do consumo regional. Nos primeiros meses do ano de 1722, o abaixamento do consumo era um tema recorrente em todas as missivas com as provedorias arrendadas e com as administrações, sem exceção. A contração do consumo, imputada ao aumento do preço e às vendas ilegais no final do contrato passado, repercutia-se no envio para Lisboa de mensalidades incompletas ou de receitas de vendas abaixo das expectativas. ${ }^{51}$

De Bruijn e Cloots responderam a esta adversidade de duas formas. Com os rendeiros a norte do Tejo, mostraram-se pouco sensíveis ao argumento da quebra de consumo para justificar o envio de créditos inferiores ao preço do arrendamento. Recordaram-lhes que tinham assumido o risco da exploração do negócio cientes dos novos preços, pelo que a quebra de consumo não podia ser invocada como argumento. Pressionaram-nos, pois, a cumprir os termos negociados nas respetivas escrituras públicas e adiantar as verbas remanescentes para satisfazer as mensalidades, tanto

49 ANTT, JAT, liv. 206, fl. 126, carta a Hayward \& Rider, ilha da Madeira, 1722-06-22.

50 ANTT, JAT, maço 11, consulta de 1721-12-20.

51 ANTT, JAT, liv. 206, fl. 44v, carta a José de Pessoa Leão, Torres Vedras, 1722-02-14; idem, fl. 45, carta a José Cristóvão da Costa, Santarém, 1722-02-14; idem fl. 46, carta a Manuel da Cruz Mascarenhas, Coimbra, 1722-02-14; idem, fl. 92v, carta a Baltazar Lopes Franco, Lamego, 1722-05-09; idem, fl. 117, carta a Manuel da Cruz Mascarenhas, 1722-06-11. 
mais que já haviam recebido remessas antecipadas de tabaco. ${ }^{52}$ Diga-se, a este respeito, que era obrigação dos contratadores-gerais ir remetendo tabaco para as provedorias na proporção do preço da arrematação da provedoria, admitindo-se apenas variações nas qualidades de tabaco, mediante informações relativamente às preferências do consumo local. ${ }^{53}$

Como seria de esperar, a resposta de De Bruijn e Cloots perante a quebra do consumo foi distinta nas provedorias que mantiveram em exploração direta. Dos seus administradores exigiram proatividade na busca de soluções que estimulassem as vendas. Para esse efeito, fizeram frequentes recomendações para que se criassem novos estancos, isto é, novos pontos de venda a retalho, por forma a angariar mais consumidores e a alargar a área geográfica da distribuição no interior de cada provedoria. ${ }^{54}$ Ainda para aumentar o consumo e assegurar o envio atempado dos créditos, a partir de Abril de 1722 puseram em prática medidas que, visando tornar mais eficiente a organização das vendas a retalho, tocaram no relacionamento entre os administradores e os estanqueiros. Os primeiros deveriam fixar quotas de venda aos segundos e cobrar-lhes antecipadamente o valor dos tabacos que recebessem para venda. A fixação das quotas seria sustentada pela feitura de um mapa com a representação dos estancos, distinguindo-se aqueles de maior consumo. Medidas semelhantes já tinham sido implementadas em Lisboa desde o início do contrato, e com sucesso, a crer nas suas próprias palavras. ${ }^{55}$ Todavia, foram recebidas com resistência da parte dos administradores e forte desagrado por parte dos estanqueiros, que se ressentiram sobretudo do fim das vendas à consignação. De Bruijn e Cloots não cederam, limitando-se a dar instruções aos seus agentes para que substituíssem aqueles estanqueiros que não se quisessem conformar

52 ANTT, JAT, liv. 206, fl. 57 e 69, cartas a Manuel da Cruz Mascarenhas, Coimbra, 1722-03-07 e 1722-03-28.

53 ANTT, JAT, liv. 209, fls. 2v-3, carta a Arnaldo van Zeller, Porto, 1721-12-17; idem, liv. 206, fl. 21, carta a António Mendes Álvares, Porto, 1722-01-17; idem, fl. 21 v-22, carta a Arnaldo van Zeller, Porto, 1722-01-17.

54 ANTT, JAT, liv. 206, fl. $41 \mathrm{v}$, carta a António Rodrigues da Santa, Portalegre, 1722-02-10; idem, fl. 46v, carta a José Rebelo, Estremoz, 1722-02-16; idem, fl. 47v, carta a Bento de Araújo Barbosa, Faro, 1722-02-16; idem, fl. 87v, carta a Silvestre de Morais Pimentel, Évora, 1722-04-28.

55 ANTT, JAT, liv. 206, fl. 92, carta a Bento de Araújo Barbosa, Faro, 1722-05-05; idem, fl. 92v carta a João Rodrigues Bagulho, Elvas, 1722-05-05; idem, fl. 97v, carta a José Francisco Gomes, Beja, 1722-05-12; idem, fl. 97v-98, carta a José Rebelo Pereira, Estremoz, 1722-05-12; idem, fl. 106v, carta a José Francisco Gomes, Beja, 1722-05-26. 
com a nova organização. ${ }^{56}$ Se estas medidas contribuíram para o aumento do consumo nestas provedorias ainda não é possível determinar.

$\mathrm{Na}$ defesa do consumo e da integridade do estanco, a preocupação com a circulação de tabaco ilegal está muito presente nas instruções enviadas a comarqueiros e administradores. Esta categoria compreende situações muito diversas, a começar pelo tabaco estrangeiro, de Virgínia ou espanhol, cuja venda e consumo estavam proibidos. Também o tabaco vindo do Brasil, desde que não tivesse saído das fábricas de Lisboa ou do Porto era considerado de contrabando. Há ecos destas ocorrências para o ano de 1722, em que tabaco brasileiro, originalmente destinado à reexportação, foi reintroduzido clandestinamente no mercado doméstico, designadamente pelos portos do Algarve. ${ }^{57}$ Por fim, também o tabaco pertencente ao contratador cessante e que tivesse sido colocado no mercado a um preço abaixo do preço tabelado se incluía nesta categoria. Se esta era uma prática comum na transição entre contratos, no caso vertente atingiu proporções inauditas, justificadas também pelo desejo dos consumidores em se aprovisionarem antes da entrada em vigor do novo tabelamento de preços. No Porto, sabemos que a venda ilegal envolveu 200.000 libras de tabaco em pó, o equivalente a 23 por cento do consumo anual do reino. ${ }^{58}$ Se no Porto e nas provedorias do Norte este fenómeno foi particularmente gravoso para De Bruijn e Cloots, nas do Sul também esteve presente a uma escala menor. Ainda em Maio de 1722, tabaco em pó do contratador passado circulava, em Faro, em unidades de uma libra, com sinete do contratador atual sobreposto ao do contratador passado. ${ }^{59}$

Perante as notícias da circulação de tabaco ilegal no estanco, os contratadores holandeses recomendaram medidas preventivas de fiscalização. Nas primeiras semanas do contrato, instruíram os seus administradores para que fizessem buscas gerais nos estancos, conferindo as quantidades e qualidades de tabaco que estivessem na sua posse, e procedendo, sempre que necessário, à substituição de estanqueiros do contratador-geral antecedente. ${ }^{60} \mathrm{~A}$ todos recomendavam também a constituição de uma rede de informadores permanentes -'espias' -, que reportassem a venda e o

56 ANTT, JAT, liv. 206, fl. 93v, carta a José Francisco Gomes, Beja, 1722-05-08.

57 ANTT, JAT, liv. 206, fls. 46 e 72, cartas a José Francisco Gomes, Beja, 1722-02-16 e 1722 03-13; idem, fl. 116, carta a Bento Araújo Barbosa, Faro, 1722-06-09.

58 Sobre esta prática dos contratadores, veja-se SALVADO, "O estanco do tabaco em Portugal", p. 150; veja-se também MIRANDA, "Risco e expectativas".

59 ANTT, JAT, liv. 206, fl. 100v, carta a Bento de Araújo Barbosa, Faro, 1722-05-19.

60 ANTT, JAT, liv. 206, fl. 1 1v, carta a João Rodrigues Bagulho, Elvas, 1722-01-06; idem, fl. 12v, carta a Bento Vieira da Cunha, Évora, 1722-01-06. 
consumo ilegal de tabaco. "O expediente das espias boas e bem pagas é o melhor que há para se evitarem descaminhos", como escreviam ao desembargador José da Costa Ribeiro em julho de 1722. ${ }^{61}$ Este expediente era também utilizado para fiscalizar a revenda de tabaco entre provedorias, o que no quadro legal do estanco era ilegal, já que competia apenas ao contratador-geral distribuir o tabaco à escala regional. Ao abrigo das suas concessões, os rendeiros das comarcas apenas podiam vender tabaco nas circunscrições territoriais que tivessem arrematado. Situações como a reportada para Castelo Branco, onde o rendeiro estaria a utilizar estanqueiros nas zonas de fronteira com a provedoria de Portalegre, sob administração direta, para estender o seu negócio não podiam, pois, ser toleradas. ${ }^{62}$ Pese embora as muitas suspeitas e notícias sobre a venda e consumo de tabaco ilegal, não é possível medir este fenómeno e, consequentemente, o seu impacte no estanco. Como já se escreveu noutro local, apenas a venda de tabaco a preço abaixo do tabelado pelo contratador antecedente no Norte do país foi, atestadamente, um fator que contribuiu para a contração do consumo no triénio de 1722-1724. ${ }^{63}$

Atendendo à importância dos fluxos dos créditos regionais para o cumprimento das obrigações contratualizadas com a monarquia, De Bruijn e Cloots alocaram tempo e recursos para monitorizar as vendas nas provedorias. O controlo que exerceram variou, todavia, de acordo com as modalidades de exploração territorial. No caso das provedorias cedidas por contrato de subarrendamento, o rendeiro dispunha de plena autonomia para organizar a distribuição, pelo que a relação estabelecida com os rendeiros não configurava uma dependência hierárquica. Neste sentido, disponível estava apenas a monitorização informal destes indivíduos, consubstanciada por meio da regular troca de correspondência, destinada a obter informações sobre a dinâmica do consumo e assegurar o atempado pagamento das mensalidades e dos quartéis.

Diferentemente, os contratadores-gerais tinham com os administradores uma típica relação principal-agente, que pressupunha o controlo apertado da sua atuação para obviar conflitos de interesse, decorrentes da assimetria de informação. De Bruijn e Cloots impuseram fiscalizações regulares aos seus administradores do Sul do país. Mensalmente exigiam o envio de uma relação abreviada do consumo da sua unidade territorial, a completar

61 ANTT, JAT, liv. 206, fl. 157v, 1722-07-28.

62 ANTT, JAT, liv. 206, fl. 86v, carta a António Rodrigues da Santa, Portalegre, 1722-04-28.

63 MIRANDA, "Risco e expectativas". 
com uma relação discriminada por estanqueiros no final de cada trimestre. Esta última era alvo de um aturado escrutínio contabilístico pelos contratadores-gerais, destinada a detetar irregularidades nas vendas, fosse ela cometida pelo administrador, ou pelos estanqueiros. ${ }^{64} \mathrm{O}$ despedimento era a medida punitiva preconizada para todos aqueles que fossem considerados infratores. ${ }^{65}$ Periodicamente, a atividade inspetiva era feita presencialmente em Lisboa, convocando-se os administradores para apresentarem contas e receber instruções gerais e específicas. ${ }^{66}$ Com uma cadência semanal, a intensa correspondência trocada com os administradores reflete também os custos de agência em que os contratadores-gerais incorreram com a administração direta.

Por fim, a existência de um segundo centro de redistribuição de tabaco e de concentração de créditos, sediado no Porto, impôs também a necessidade de fiscalizar a informação relativa às vendas no Norte do país. Ainda que sócio, Arnaldo van Zeller estava obrigado a apresentar contas a De Bruijn e Cloots. A fiscalização fazia-se a um ritmo semestral, com o envio de contas individualizadas, relativas às receitas da fábrica e às mensalidades pagas pelas provedorias sob a sua alçada ${ }^{67} \mathrm{O}$ balanço da gestão de Arnaldo van Zeller e do impacte que possa ter tido no insucesso deste contrato ainda está por fazer. Que os sócios se desentenderam alguns meses antes do final do segundo triénio já o sabemos, devido às dívidas dos rendeiros nortenhos. As missivas trocadas entre Lisboa e Porto mostram, todavia, que as tensões no interior do consórcio começaram ainda em Dezembro de 1721, quando Arnaldo van Zeller entendeu, de motu proprio, arrendar alguns estancos da cidade do Porto. ${ }^{68} \mathrm{O}$ relacionamento manteve-se difícil ao longo da execução do primeiro triénio, facto comprovado também pela tentativa gorada que De Bruijn e Cloots fizeram para afastar van Zeller da sociedade antes do início do segundo triénio.

64 ANTT, JAT, liv. 206, fl. 107, carta a Bento Araújo Barbosa, Faro, 1722-05-26; idem, fl. 122v, carta a Bento Vieira da Cunha, Évora, 1722-06-16.

65 ANTT, JAT, liv. 206, fl. 93v, carta a José Francisco Gomes, Beja, 1722-05-08, idem, fl. 107v, carta a Bento Vieira da Cunha, Évora, 1722-05-26; idem, fl. 120, carta a Bento de Araújo Barbosa, Faro, 1722-06-16.

66 ANTT, JAT, liv. 206, fl. 88v, carta a José Rebelo Pereira, Estremoz, 1722-04-28; idem, fl. 129, carta a Gabriel Ferreira, Setúbal, 1722-06-27.

67 ANTT, JAT, liv. 206, fl. $131 \mathrm{v}$, carta a Arnaldo van Zeller, Porto, 1722-06-21.

68 ANTT, JAT, liv. 209, fls. 1v-2, 4, e 7v, cartas a Arnaldo van Zeller, Porto, 1721-12-13, 1721 12-27 e 1722-01-03. 


\section{CONCLUSÃO}

No monopólio do tabaco, a distribuição à escala nacional era, sem dúvida, o segmento mais complexo do negócio. A correspondência aqui explorada serve de testemunho aos desafios logísticos que os consórcios privados enfrentavam na coordenação das operações de transporte e venda, bem como da informação dentro do estanco. $O$ volume das missivas que De Bruijn e Cloots trocaram com cerca de três dezenas de correspondentes atestam bem, não só a exigente operacionalização deste segmento, como o tempo que the alocaram. Nesse sentido, este caso de estudo oferece um olhar único sobre as estratégias organizacionais que implementaram e sobre a prática quotidiana de gestão. Da eficaz monitorização das vendas de tabaco no reino e ilhas dos Açores e Madeira e dos regulares fluxos de créditos para Lisboa, dependia, afinal de contas, a sua capacidade de cumprir o apertado calendário de pagamentos à monarquia e o sucesso do contrato.

Cientes dos desafios e dos problemas, De Bruijn e Cloots implementaram novas soluções para a comercialização do tabaco. As inovações surpreendem-se, por um lado, na escala com que fizeram uso da administração direta, modalidade que cobriu todo o Sul do país, e, por outro, na fixação de quotas de venda aos estanqueiros nas provedorias que mantiveram sob exploração. Se estas medidas visaram aumentar o consumo e tornar mais eficiente a organização das vendas a retalho, os holandeses também se destacaram na fiscalização que impuseram aos seus agentes, estabelecendo rotinas apertadas de escrutínio.

A comparação com as provedorias do Centro e Norte do país, onde a opção foi o subarrendamento, mostra que a aposta na administração permitiu ao consórcio holandês mitigar conflitos de agência, ainda que esta asserção necessite de investigação mais aprofundada. Na verdade, se o subarrendamento permitia a partilha de riscos com o rendeiro, inibia também a capacidade fiscalizadora dos contratadores-gerais e limitava a remoção de rendeiros, em caso de incumprimento contratual. Neste último caso, a remoção só se podia processar por via judicial, desde que houvesse um cúmulo de mensalidades em dívida. Ora, mensalidades atrasadas ou incompletas foram uma marca comum a todas as provedorias arrendadas no ano de 1722, sem que, todavia, De Bruijn e Cloots pudessem contrariar esta realidade. Neste sentido, ainda que a administração direta implicasse a assunção dos custos de operacionalização da venda a retalho, não é surpreendente que, cerca de vinte mais tarde, o contratador-geral Feliciano Velho Oldenberg tenha optado por estruturar a distribuição de tabaco no território metropolitano com recurso exclusivo a administradores. 


\section{FONTES MANUSCRITAS}

Arquivo Distrital de Lisboa

- Cartórios Notariais de Lisboa, Distribuidor, liv. 85.

Arquivo Nacional da Torre do Tombo

- Junta da Administração do Tabaco:

- livros 85, 206, 208-209 e 250.

- maço 11

\section{BibLIOGRAFIA}

ANTUNES, Cátia, MIRANDA, Susana Münch e SALVADO, João Paulo (2018), "The Resources of Others: Dutch Exploitation of European Expansion and Empires, 1570-1800", Tijdschrift voor Geschiedenis, vol. 131/3, pp. 501-521.

CASSON, Mark e ROSE, Mary B. (1997), "Institutions and the Evolution of Modern Business: Introduction", Business History, vol. 39/ 4, pp. 1-8.

CASSON, Mark (1997), "Institutional Economics and Business History: A Way Forward?", Business History, vol. 39/4, pp. 151-171.

COLLI, Andrea e ROSE, Mary (2009), "Family Business", in JONES, Geoffrey G. e ZEITLIN, Jonathan, The Oxford Handbook of Business History, Oxford University Press, Oxford, pp. 194-217.

COLLI, Andrea e FERNÁNDEZ, Paloma (2013), "Business History and Family Firms", in MELIN, Leif, NORDQVIST, Mattias e SHARMA, Pramodita (eds.), Sage Handbook of Family Firms, Sage, Londres, pp. 269-292.

COSTA, Leonor Freire e SALVADO, João Paulo (2018), "Consumo, inovação organizacional e fiscalidade do tabaco em Portugal, 1701-1803", in LUXÁN, Santiago de e FIGUEIROA-REGO, João (eds.), El tabaco y la esclavitud en la rearticulación imperial ibérica (ss. XV-XX), CIDEHUS / Universidade de Évora, Évora.

ESCOBEDO, Rafael (2006), "La desprivatización de la hacienda española durante el siglo XVIII: el ejemplo del monopolio de tabacos", Empresa y Humanismo, vol. 8/2, pp. 35-66.

GELDERBLOM, Oscar (2003), "The Governance of Early Modern Trade: The Case of Hans Thijs, 1556-1611", Enterprise and Society, vol. 4/4, pp. 606-639.

GELDERBLOM, Oscar e TRIVELLATO, Francesca (2018), "The Business History of the Preindustrial World: Towards a Comparative Historical Analysis," Business History, vol. 60/5, pp. 1-35. 
HANCOCK, David (2002),"'An Undiscovered Ocean of Commerce Laid Open': India, Wine and the Emerging Atlantic Economy, 1703-1813", in BOWEN, Huw V., LINCOLN, Margarette e RIGBY, Nigel (eds.), The Worlds of the East India Company, Boydell Press, Woodbridge, pp. 153-168.

JONES, Stephen (1997), "Transaction Costs and the Theory of the Firm: The Scope and Limitations of the Institutional Approach", Business History, vol. 39/4, pp. 9-25.

MACHADO, Margarida (2018), "Os contratadores do tabaco nos arquipélagos atlânticos dos Açores e da Madeira", in LUXÁN, Santiago e FIGUEIROA-REGO, João (eds.), El tabaco y la esclavitud en la rearticulación imperial ibérica (ss. XV-XX), CIDEHUS / Universidade de Évora, Évora.

MATHIAS, Peter (2000), "Risk, Credit and Kinship in Early Modern Enterprise", in McCUSKER, John e MORGAN, Kenneth (eds.), The Early Modern Atlantic Economy, Cambridge University Press, Cambridge, pp. 15-35.

MATOS, Artur Teodoro de (1980), Transportes e comunicações em Portugal, Açores e Madeira (1750-1850), Universidade dos Açores, Ponta Delgada.

MIRANDA, Susana Münch (2018), "Risco e expectativas no monopólio português do tabaco, 1722-1727", in LUXÁN, Santiago de FIGUEIROAREGO, João (eds.), El tabaco y la esclavitud en la rearticulación imperial ibérica (ss. XV-XX), CIDEHUS / Universidade de Évora, Évora.

NARDI, Jean-Baptiste (1996), O fumo brasileiro no período colonial: lavoura, comércio e administração, Editora Brasiliense, São Paulo.

NARDI, Jean-Baptiste (1990), "Retrato de uma indústria no Antigo Regime: o estanco real do tabaco em Portugal, (1675-1830)", Arquivos do Centro Cultural Português, vol. 28, pp. 321-339.

NETO, Margarida Sobral (2005), "Os correios na Idade Moderna", in NETO, Margarida Sobral, (ed.), As comunicações na ldade Moderna, Fundação Portuguesa das Comunicações, Lisboa, pp. 16-74.

NORTH, Douglass C. (1981), Structure and Change in Economic History, W.W. Norton \& Co., New York.

PRICE, Jacob (1990), "Transaction Costs: A Note on Merchant Credit and the Organization of Private Trade", in TRACY, James (ed.), The Rise of Merchant Empires: Long-Distance Trade in the Early Modern World, 13501750, Cambridge University Press, Cambridge, pp. 276-297.

PRICE, Jacob (1995), "Tobacco Use and Tobacco Taxation: A Battle of Interests in Early Modern Europe", in GOODMAN, Jordan, LOVEJOY, Paul E. e SHERRATT, Andrew (eds.), Consuming Habits: Drugs in History and Anthropology, Routledge, Londres, pp. 165-85. 
ROCHA, Manuela e SOUSA, Rita Martins de (2005), "Moeda e crédito", in LAINS, Pedro e SILVA, Álvaro Ferreira da (eds.), História Económica de Portugal (1700-2000), Imprensa de Ciências Sociais, Lisboa, pp. 209-236. RODRÍGUEZ GORDILLO, José Manuel (2000), "El abastecimiento de tabacos del Brasil a las Reales Fábricas de Sevilla en el primer tercio del siglo XVIII" in Actas del Coloquio de Historia Canario-Americana, Cabildo Insular de Gran Canaria, Las Palmas de Gran Canaria, pp. 1871-1887.

SAFLEY, Thomas Max (2009), "Business Failure and Civil Scandal in Early Modern Europe", Business History Review, vol. 83/1, pp. 35-60.

SALVADO, João Paulo (2014), "O estanco do tabaco em Portugal: contrato-geral e consórcios mercantis (1720-1755)", in LUXÁN, Santiago de (ed.), Política y Hacienda del tabaco en los imperios ibéricos (siglos XVII-XIX), Centro de Estudios Políticos e Constitucionales, Madrid, pp. 137-144.

SALVADO, João Paulo (2018), "Uma revolução de escala? O impacte do estanco no comércio de tabaco brasileiro (Lisboa, primeira metade do século XVIII)", in LUXÁN, Santiago de FIGUEIROA-REGO, João (eds.), El tabaco y la esclavitud en la rearticulación imperial ibérica (ss. XV-XX), CIDEHUS / Universidade de Évora, Évora.

SCHWARTZ, Stuart B. (1984), "Colonial Brazil, Plantations and Peripheries, c. 1580-c. 1750", in BETHELL, Leslie (ed.), The Cambridge History of Latin America. Colonial Latin America, vol. 2, Cambridge University Press,Cambridge, pp. 423-499 